\title{
When is meconium stained liquor actually bile stained vomit?
}

\author{
D M GRIFFITHS AND D M BURGE
}

Wessex Regional Centre for Paediatric Surgery, Southampton General Hospital, Southampton

SUMMARY Three babies said to have had 'meconium stained liquor' were subsequently found never to have passed meconium. The green discoloured liquor was the result of bilious vomiting in utero secondary to intestinal obstruction.

\section{Case reports}

\section{CASE 1}

After an uneventful pregnancy during which no ultrasound scans had been performed, a baby boy was born at term, and meconium stained liquor was noted. He fed well and was discharged home after 24 hours. At 4 days of age he began to vomit green, and then brown, smelly fluid. On admission he was severely shocked with gross, tense abdominal distension. After vigorous resuscitation laparotomy was performed; a cavity filled with pus was found in the left upper quadrant caused by an antenatal perforation of the jejunum. Distal to the perforation the bowel was full of inspissated pellets, characteristic of meconium ileus. The colon was narrow and empty. The jejunal perforation was resected and a Bishop-Koop jejunostomy performed. He died 48 hours postoperatively of septicaemia and shock lung. Necropsy showed the histological features of cystic fibrosis.

\section{CASE 2}

After an antenatal ultrasound scan at 32 weeks that showed distended loops of bowel a baby boy was delivered by emergency caesarean section because of fetal distress during labour. There was meconium stained liquor. He had a distended abdomen with an umbilical flare and was given antibiotics. Meconium was thought to have been found in the rectum on rectal examination. After intubation he was transferred to the regional unit and after further resuscitation laparotomy was performed; this showed a meconium peritonitis cyst containing $300 \mathrm{ml}$ of brown offensive fluid. There was a volvulus of the jejunum $5 \mathrm{~cm}$ distal to the duodenojejunal flexure. The rest of the ileum was normal, but full of inspissated pellets. There was a typical narrow, empty colon. The necrotic loop of jejunum was resected and a Bishop-Koop jejunostomy performed that was closed when the baby was 3 months old. The diagnosis of cystic fibrosis was confirmed by sweat test, and he was growing well at 12 months of age.

CASE 3

After antenatal diagnosis of a large bladder and bilateral hydronephrosis a baby boy had two vesicoamniotic shunts inserted at 30 and 32 weeks' gestation. Gross polyhydramnios was noted. At delivery at 35 weeks, fresh 'meconium' was noted and the cord was wrapped tightly round him. He required intubation and ventilation for a short period.

On examination he had multiple intradermal haemorrhages on his face from the cord, and the abdominal wall was typical of the prune belly syndrome. Both kidneys and the huge bladder were easily palpable. The initial diagnosis of urinary obstruction by posterior urethral valves was refuted by the micturating cystogram which showed gross unobstructed megacystis without vesicoureteric reflux. Bile stained vomiting started after 36 hours and the diagnosis of megacystis microcolon intestinal hypoperistalsis syndrome was confirmed by barium enema examination (which showed a narrow colon) and by barium meal examination (which showed extremely slow transit into the jejunum). He died shortly afterwards.

\section{Discussion}

Meconium stained liquor is a classic sign of fetal distress during labour. The liquor is green or brown and fills the pharynx and stomach, and in some cases the trachea and bronchial tree. Because of the need to ensure that the lungs are clear, paediatricians are called to deliveries at which meconium stained liquor is found so that they may aspirate the trachea either under direct vision or through an endotracheal tube, thus preventing meconium pneumonitis. All three cases reported here were seen by a paediatric team, one before discharge home, and all three before transfer to the regional unit. If the lack of meconium in the rectum in these children with apparent meconium stained liquor had been detected early, it might have alerted their clinicians to the possibility of intestinal obstruction. The operative and radiological findings in each case indicated that meconium could never have been 
passed rectally. Earlier diagnosis might have resulted in the survival of case 1 , and reduced the morbidity in case 2 .

If a rectal thermometer is passed and the end inspected, it not only allows a check on the colour of the rectal contents (if any) but also ensures that any anorectal abnormality is detected immediately. The paediatrician called to the delivery should do this himself.
Absence of meconium in the rectum should alert the paediatrician to the possibility that the baby does not have meconium stained liquor, but intestinal obstruction with bile stained vomiting in utero.

Correspondence to Mr DM Burge, Wessex Regional Centre for Paediatric Surgery, Southampton General Hospital, Southampton SO9 $4 \mathrm{XY}$.

Received 12 May 1987

\title{
Mercury concentration in cord blood
}

\author{
D A SPENCER, ${ }^{*}$ I M HOUSE, $\dagger \mathrm{J}$ H TRIPP, $\ddagger$ AND L STIMMLER $*$
}

${ }^{*}$ Departments of Paediatrics, Guy’s Hospital, and $\ddagger$ Royal Devon and Exeter Hospitals, and $†$ Poisons Unit, Lewisham and North Southwark Health Authority

SUMMARY The mean mercury concentration measured in cord blood from 51 inner city babies born at Guy's Hospital was significantly higher $(37 \mathrm{nmol} / \mathrm{l} v$ $20 \mathrm{nmol} / \mathrm{l}$ ) than that from 17 babies born at the Royal Devon and Exeter Hospital, which serves a more rural population.

The finding of a mercury concentration well above that believed to be 'normal' (from experience with adults) in the cord blood from an infant at Guy's Hospital who died during the neonatal period prompted a literature search for normal values in cord blood. None were found for infants in the United Kingdom, though values are published from other parts of the world, particularly where mercury toxicity is a recognised problem. ${ }^{1}$ Analysis, for mercury, of cord bloods from other babies at the hospital (which serves an area of inner London) showed an unexpectedly high mean concentration; this suggested the possibility of environment exposure and prompted a comparison study with infants born in a rural environment.

\section{Patients and methods}

Samples of cord blood $(5 \mathrm{ml})$ were obtained from 51 randomly selected babies of normal deliveries at Guy's Hospital from patients living in inner London and from 17 deliveries at the Royal Devon and Exeter Hospital, which serves a rural environment. In both centres the samples were taken from fresh placentas by needle puncture of a placental vein. The specimens were immediately transferred to a heparinised blood tube and stored at $-20^{\circ}$ until analysed by one of us (IMH). No information was collected about mothers in relation to possible environmental or occupational exposure to mercury.

Total whole blood mercury was measured by cold vapour atomic absorption spectrometry with a Varian 475 spectrometer by an unpublished method, based on that of Hatch and Ott, ${ }^{2}$ after destruction of the organic material in the samples with a mixture of nitric and sulphuric acids and potassium permanganate. The limit of detection of the method varied between 2.5 and $7.5 \mathrm{nmol} / \mathrm{l}$ with a coefficient of variation of $20 \%$ at $25 \mathrm{nmol} / 1$. An internal quality control sample that was measured periodically gave a mean (SD) of $50(2.5) \mathrm{nmol} / \mathrm{l}$. Statistical analysis was by Student's $t$ test after log transformation of the data.

\section{Results}

Mercury concentrations in cord blood from samples from the rural population were normally distributed about a geometric mean of $20 \mathrm{nmol} / \mathrm{l}(95 \%$ range 11-36 nmol/l). Mercury concentrations in the samples from the inner London population had a skewed distribution with a geometric mean of $37 \mathrm{nmol} / \mathrm{l}(95 \%$ range $10-139 \mathrm{nmol} / \mathrm{l})$ (figure). There was a significant difference between the means of the two groups $(t=9 \cdot 63 ; d f=67 ; p<0.00001)$.

\section{Discussion}

The pathophysiological importance of these findings is unclear. Mercury toxicity is unlikely below a blood concentration of $1000 \mathrm{nmol} / 1,{ }^{3}$ though Pink disease can be seen in infants and children at 